\title{
Novel Batch Titanium Nitride CVD Process for Advanced Metal Electrodes
}

\author{
Peter Zagwijn ${ }^{1 *}$, Wilco Verweij ${ }^{1}$, Dieter Pierreux ${ }^{1}$, Noureddine Adjeroud ${ }^{1}$, \\ Radko Bankras ${ }^{1}$, Ed Oosterlaken ${ }^{1}$, Gert Jan Snijders ${ }^{1}$, Michiel van den Hout ${ }^{2}$, \\ Pamela Fischer ${ }^{1}$, Rudi Wilhelm ${ }^{1}$, Martin Knapp ${ }^{1}$ \\ ${ }^{1}$ ASM International N.V., Bilthoven, The Netherlands \\ ${ }^{2}$ Delft University of Technology, Delft, The Netherlands
}

This article describes a novel CVD process for Titanium Nitride (TiN) films developed in a $300 \mathrm{~mm}$ vertical furnace. We have solved Chlorine incorporation at low temperature inside the TiN layer while at the same time the batch process yields a 3 times higher throughput per dual reactor system compared to a single wafer system with 3 chambers. We show process results for load sizes ranging from 5 to as much as 100 wafers that prove filler wafers are only required to a minimum. Applications with the developed TiN process are in Metal-Insulator-Metal memory devices such as Stack DRAM, and embedded DRAM.

\section{Introduction}

Memory devices for the generations beyond $65 \mathrm{~nm}$ will be based on Metal Insulator Metal (MIM) capacitor cell structures. The most promising candidate for both metal electrodes (top and bottom) is Titanium Nitride (TiN) as shown for instance by the ITRS roadmap for Front End Processes [1]. A significant part of these electrodes are applied in the DRAM memory cell [2,3]. But also in gate stack development for advanced CMOS beyond $45 \mathrm{~nm}$ technology node TiN is widely used as mid-gap metal gate electrode [4]. The material is applied as control gate electrode in NAND Flash [5], as well as heater electrode and control gate electrodes in phase change memory [6]. Furthermore next generation MIM capacitors for embedded Memory devices target TiN as the electrode material. Historically metal nitrides were deposited by single wafer deposition tools. This article describes a novel CVD process for TiN films developed for the first time in a 300 $\mathrm{mm}$ vertical furnace at low pressure.

\section{Chemical Vapor Deposition}

TiN films can be grown by conventional CVD using $\mathrm{TiCl}_{4}$ and $\mathrm{NH}_{3}$. The resulting resistivity of the film is too high for the application as electrode material in semiconductor devices. Therefore we used a pulsed CVD process [Fig. 1].

\footnotetext{
* Contact Author: e-mail: peter.zagwijn@asm.com
} 


\begin{tabular}{|l|c|c|c|}
\hline $\mathrm{TiCl}_{4}+\mathrm{NH}_{3}$ & $\mathrm{~N}_{2}$ purge & $\mathrm{NH}_{3}$ & $\mathrm{~N}_{2}$ purge \\
\hline CVD step & Flush step
\end{tabular}

Figure 1. The novel batch CVD process for TiN. The first part of the cyclic process is a true CVD step; the second part is a selflimiting $\mathrm{NH}_{3}$ flush step.

After a TiN CVD step that typically grows a thin film of $1 \AA$, the gases are purged out of the reactor and a $\mathrm{NH}_{3}$ flush step is introduced resulting in a thin uniform film. The second step is a self-limiting step. The cycle is than repeated until the required film thickness has been reached. The process window is broad and has been investigated in the temperature range of 350 to $500^{\circ} \mathrm{C}$. A lower temperature than $500{ }^{\circ} \mathrm{C}$ yields more $\mathrm{Cl}$ trapped in the growing film and thus a higher film resistivity. TiN films grown in conventional ALD-mode with $\mathrm{TiCl}_{4}$ and $\mathrm{NH}_{3}$ have a major disadvantage in the growth per cycle of only $0.2 \AA$ [7].

\section{Reactor}

The process was developed in a dedicated reactor that is part of the A412 vertical furnace platform: A quad boat dual reactor vertical batch furnace for high volume manufacturing. This system is described in detail elsewhere [8]. Next to the use of a conventional heater and quartz walled tube that forms the reactor chamber inner wall a multi-hole injector system inside the reactor chamber has been introduced. $\mathrm{TiCl}_{4}$ delivery was done by means of a commercially available direct liquid injection system capable of delivering up to $1.5 \mathrm{~g} / \mathrm{min}$ of $\mathrm{TiCl}_{4}$ pre-cursor. Such a system consists of a liquid flow controller, a vaporizer and a mass flow meter downstream of it. $\mathrm{NH}_{3}$ gas of semiconductor grade is delivered by conventional mass flow control units. The pressure in the reactor is controlled in a range between 10 and 10000 mTorr with an accuracy of \pm $1 \mathrm{mTorr}$. To prevent particle formation by peeling of the grown TiN film on the quartz, a thermally activated in situ cleaning process has been developed using $\mathrm{NF}_{3}$ and $\mathrm{Cl}_{2}$ gases to remove TiN effectively from the chamber walls. The lower part of the reactor chamber is sealed of by a vacuum door plate that is heated by resistive electrical heating to prevent condensation reaction byproducts. A high purity $\mathrm{N}_{2}$ purged mini-environment controls the $\mathrm{O}_{2}$ levels well below $10 \mathrm{ppm}$. This is very important to keep the resulting resistivity of the film in control. An experiment was performed to establish the influence of $\mathrm{O}_{2}$ level in the mini-environment below the closed entrance of the reactor both during processing as well as during the so-called "boat-out" step of the process recipe in which the carrier with silicon wafers is lowered about $1300 \mathrm{~mm}$ down from the reactor at a speed of $100 \mathrm{~mm} / \mathrm{min}$. During this lowering the wafers start cooling down in the mini-environment from $300{ }^{\circ} \mathrm{C}$ to room temperature. In Table I the effect on resistivity has been given for a high $\mathrm{O}_{2}$ concentration $(>1000 \mathrm{ppm})$ in the mini-environment and a well controlled minienvironment with $\mathrm{O}_{2}$ levels at $12 \mathrm{ppm}$. 


\begin{tabular}{|c|c|c|c|c|}
\hline \multicolumn{5}{|c|}{ TABLE I. $\mathrm{O}_{2}$ level experiment } \\
\hline $\begin{array}{c}\mathrm{O}_{2} \text { level } \\
\text { during } \\
\text { Deposition } \\
\left(@ 500{ }^{\circ} \mathrm{C}\right)\end{array}$ & $\begin{array}{c}\mathrm{O}_{2} \text { level } \\
\text { during } \\
\text { "Boat- } \\
\text { out" } \\
\left(\text { (a) } 300{ }^{\circ} \mathrm{C}\right)\end{array}$ & $\begin{array}{c}\text { TiN Rs } \\
\left(\Omega_{\text {sq }}\right) \\
\text { Bottom } \\
\text { Wafer }\end{array}$ & $\begin{array}{c}\text { TiN Rs } \\
\left(\Omega_{\text {sq }}\right) \\
\text { Centre } \\
\text { Wafer }\end{array}$ & $\begin{array}{c}\text { TiN Rs } \\
\left(\Omega_{\text {sq }}\right) \\
\text { Top } \\
\text { Wafer }\end{array}$ \\
\hline$>1000 \mathrm{ppm}$ & $>1000 \mathrm{ppm}$ & 610 & 721 & 945 \\
\hline$>1000 \mathrm{ppm}$ & $13 \mathrm{ppm}$ & 315 & 378 & 403 \\
\hline $12 \mathrm{pmm}$ & $12 \mathrm{ppm}$ & 284 & 291 & 297 \\
\hline
\end{tabular}

Clearly the effect on sheet resistance is present when $\mathrm{O}_{2}$ level is high. The wafer that is introduced into the mini-environment last with relative highest temperature (i.e. the top wafer in the carrier) has highest $R_{s}$ value.

\section{Productivity}

The flexibility in load size is illustrated in Figure 2 where the deposited thicknesses for 3 different Product wafer load size processes with one and the same recipe are given.

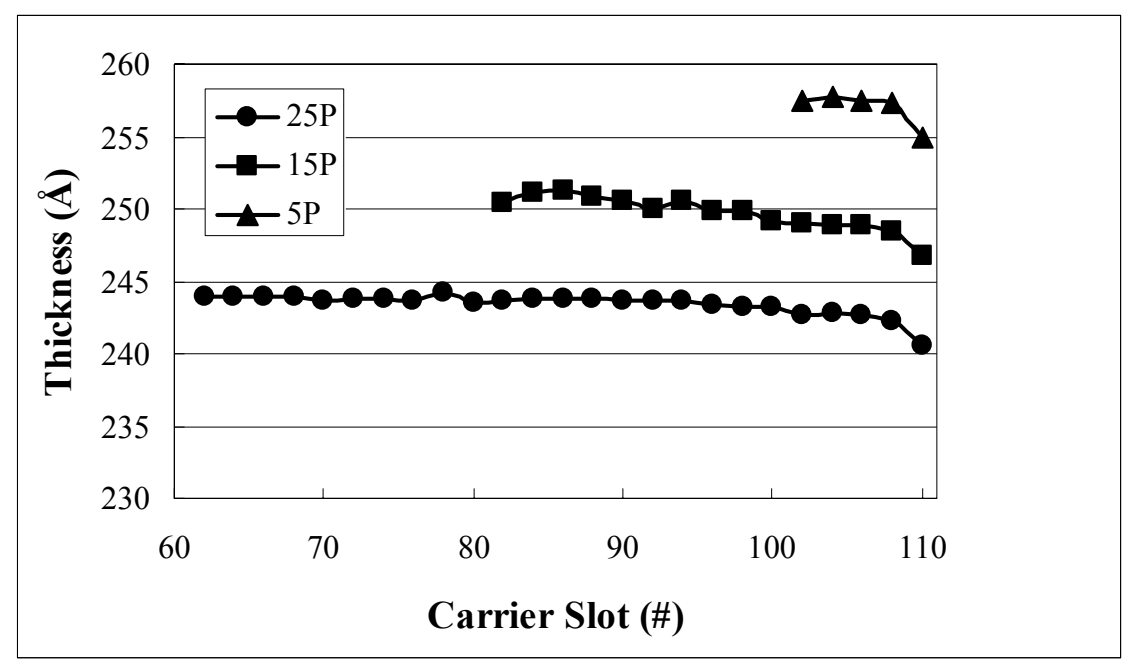

Figure 2. Flexible load size performance of the pulsed CVD TiN process for 5, 10 and 25 Product wafers in the furnace.

Per Product wafer a constant decrease of $0.7 \AA$ in thickness is measured. For the 3 different load sizes only 3 filler wafers were used. Slot 60 corresponds to the centre of the reactor. Slot 110 is the top of the furnace. For films with a thickness of $10 \mathrm{~nm}$ the dual reactor system produces as much as 75 wafers per hour. This is about 3 times higher a throughput per dual reactor system than the combined throughput of a single wafer system with 3 chambers. 


\section{Composition}

Stochiometric TiN films are generated with thickness uniformities of $1 \%$ range using the pulsed CVD process at $500{ }^{\circ} \mathrm{C}$ deposition temperature. The results of Auger analysis on film composition are given in Table 2 . The Chlorine contamination is well below 1 at.\%. Depth XPS measurements confirmed the low $\mathrm{Cl}$ content below 1\%.

\begin{tabular}{|c|c|c|c|}
\hline \multicolumn{5}{|c|}{ TABLE II. Composition analysis } \\
\hline Element & Wafer Top & Wafer Bottom & Reference \\
\hline $\mathrm{Ti}(\%)$ & 48.7 & 49.0 & 47.5 \\
\hline $\mathrm{N}(\%)$ & 49.0 & 49.0 & 47.5 \\
\hline $\mathrm{O}(\%)$ & 1.6 & 1.3 & 2.0 \\
\hline $\mathrm{Cl}(\%)$ & 0.7 & 0.7 & 3.0 \\
\hline $\mathrm{N}: \mathrm{Ti}$ & 1.01 & 1.00 & 1.00 \\
\hline
\end{tabular}

The last row contains the ratio between the Nitrogen and Titanium elements. The column on the right contains reference data of a single wafer deposition system.

The low concentration of $\mathrm{Cl}$ in the film is a result of the two step process where the self-limiting $\mathrm{NH}_{3}$ flush following the CVD deposition step removes most of the $\mathrm{Cl}$ content from the freshly deposited TiN layer. As a result he thin film resistivity value of these films measure as low as $150 \mu \Omega \mathrm{cm}$. When the ratio of the $\mathrm{NH}_{3}$ flush step time vs. the $\mathrm{TiCl}_{4}+\mathrm{NH}_{3} \mathrm{CVD}$ step time is reduced from 2:1 to $1: 1$ the resistivity increases by a factor 2 due to the increased Chlorine content of the film.

\section{Conformality}

In memory structures the conformality of the electrodes are essential for proper electrical performance, minimizing the variation of resistivity. Conformality in this paper is defined as $100 \%$ minus the relative maximum full range of the thicknesses of the film measured in the top, center and bottom of the trench respectively. Step coverage is the ratio between the thickness of the film deposited on the sidewalls of the trench structures and the thickness of the film deposited on the surface of the wafer. Step coverage in the range of 85 to $95 \%$ is measured for an aspect ratio (AR) up to 40:1. Although the TiN film is grown in CVD-mode even films in deep trenches with high aspect ratio $(\mathrm{AR}=80: 1)$ have been successfully deposited in a 100 wafer load batch with good step coverage and conformality within the trench higher than $80 \%$. In Figure 3 the cross-section SEM image is shown for a pulsed-CVD 50nm TiN film grown at $500^{\circ} \mathrm{C}$ in an $\mathrm{AR}=32: 1$ trench. The conformality observed is $>92 \%$. 


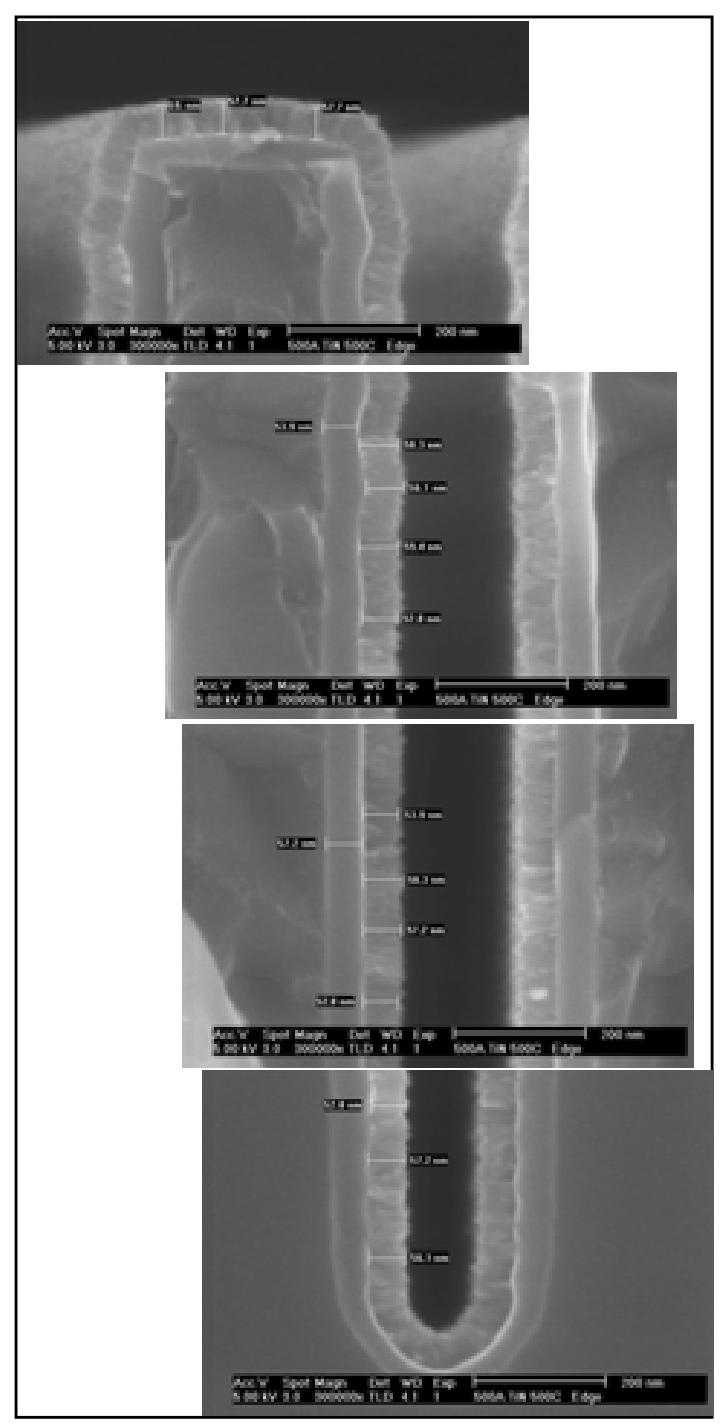

Figure 3. Cross-section SEM analysis of 50nm thick TiN deposited by pulsed-CVD in a trench with $\mathrm{AR}=32: 1$. A conformality $>92 \%$ is measured.

\section{Conclusions}

We have developed a novel batch CVD process for low resistivity TiN films using a $300 \mathrm{~mm}$ vertical furnace. The reactor hardware has been specially designed to yield low particle performance and ease of maintenance for the TiN process. The pulsed CVD process results in highly conformal, stochiometric layers with low Chlorine $(<1 \%)$ and low Oxygen $(<1.7 \%)$ concentrations and uniform thickness distribution within the 300 $\mathrm{mm}$ silicon wafers processed in the reactor. A dedicated injection system enables high uniformity of deposited films on 100 product wafers distributed from bottom to top of the furnace and results in productivity of the dual reactor system of over 75 wafers per hour. 


\section{References}

1. International Technology Roadmap for Semiconductors Front End Processes, (2007).

2. K. Kim, G. Jeong, IEDM Technical Digest, 27 (2007).

3. L. Heineck, W. Graf, M. Popp, D. Savignac, H.-P. Moll, R. Tews, D. Temmler, G. Kar, J. Schmid, M. Rouhanian, I. Uhlig, M. Goldbach. E. Landgraf, L. Dreeskornfeld, M. Drubba, S. Lukas, D. Weinmann, W. Roesner, W. Mueller, IEDM Technical Digest, 31 (2007).

4. V. Barral, T. Poiroux, F. Andrieu, C. Buj-Dufournet, O. Faynot, T. Ernst, L. Brevard, C. Fenouillet-Beranger, D. Lafond, J.M. Hartmann, V. Vidall, F. Allain, N. Daval, Cayrefourcq, L. Tosti, D. Munteanu, J.L. Autran, S. Deleonibus, IEDM Technical Digest, 61 (2007).

5. G. Molas, M. Bocquet, J. Buckley, J. P. Colonna, L. Masarotto, H. Grampeix, F. Martin, V. Vidal, A. Toffoli, P. Brianceau, L. Vermande, P. Scheiblin, M. Gély, A. M. Papon, G. Auvert, L. Perniola, C. Licitra, T. Veyron, N. Rochat, C. Bongiorno, S. Lombardo, B. De Salvo, S. Deleonibus, IEDM Technical Digest, 453 (2007).

6. T. Nirschl, J. B. Philipp, T. D. Happ, G. W. Burr, B. Rajendran, M.-H. Lee, A. Schrott, M. Yang, M. Breitwisch, C.-F. Chen, E. Joseph, M. Lamorey, R. Cheek, S.-H. Chen, S. Zaidi, S. Raoux, Y.C. Chen, Y. Zhu, R. Bergmann, H.-L. Lung, C. Lam, IEDM Technical Digest, 461 (2007).

7. E. Granneman, D. Pierreux, P. Fischer, H. Terhorst, P. Zagwijn, Surface \& Coatings Technology, 201, 8899 (2007).

8. R. de Blank, F. Huussen, E. Oosterlaken, P. Zagwijn, T. Claasen-Vujcic, A. Hasper, European Semiconductor 5/2001, 29 (2001). 